\title{
CONGENITAL HEART DISEASE IN ONE OF UNIOVULAR TWINS
}

\author{
BY \\ GEOFFREY WADE \\ From the Department of Cardiology, the University of Manchester \\ Received February 6, 1952
}

Many cases have been reported of congenital heart disease occurring in both of uniovular twins. With the exception of dextrocardia occurring as part of situs inversus (Debreuil-Chambardel, 1927), no cases have been reported in which the lesion has been confined to one of such twins. As uniovular twins are usually similar in size as well as appearance (Stocks, 1930) the occurrence of a defect in one would be a valuable natural experiment yielding information regarding the effects of the lesion upon development. It would also throw further light upon the hereditary factors governing the transmission of the defect.

A lesion causing growth impairment in one of monozygotic twins is also rare. Milne (1951), reporting two pairs of twins in whom growth disparity was due to renal dwarfism, noted four other reported cases. Two were due to skeletal deformities (Siemens, 1927; Lehmann, 1937) and two were due to endocrine dysfunction (Komai and Fukuoka, 1934; Lewis, 1936). A further case, due to congenital syphilis, has been reported by Penrose (1937).

Two cases of congenital heart disease occurring in only one of a pair of twins believed to be uniovular are reported in this paper. In one the lesion was a patent ductus arteriosus and observations have been made on the development of this child and of her twin over a period of $2 \frac{1}{2}$ years after successful ligation of the ductus. In the other the lesion was thought to be isolated pulmonary stenosis.

\section{CASE REPORTS}

Case 1. The patient was a seven-year-old girl, one of a family of nine, and had a twin sister. Both weighed $6 \frac{1}{4} \mathrm{lb}$. at birth. Pregnancy and confinement were uneventful. When two years old she was admitted to hospital on account of a respiratory infection and a heart murmur was heard. She had otherwise enjoyed good health but had always been smaller and less active than her twin.

On examination she was a slender girl. There was a systolic-diastolic murmur loudest in the second left interspace characteristic of a patent ductus arteriosus. The blood pressure was $125 / 60 \mathrm{~mm}$. A teleradiogram showed some prominence of the pulmonary artery, a rather small aorta, and a cardiothoracic ratio of $0 \cdot 62$. The electrocardiogram was within normal limits.

The ductus was ligated by Mr. Graham Bryce, and convalescence was uneventful. When last seen two and a half years later her mother stated that she was more active than her twin sister.

Comparison of the twin. The twin sister was a normal healthy girl. A radiological examination was not made at the time of the first visit. Fig. 1 shows comparative teleradiograms 14 months after operation. The heart of the normal child is still smaller, though as usual the heart of the sister had diminished in size after the closure of the ductus.

Apart from the difference in physique, the children were very similar. The shape of the head and ears, the colour and distribution of the hair, the colour of the eyes, and the dental patterns were alike. The finger prints were reported on as follows: "The ridge characteristics do not fall on the same sequence and therefore the prints are not identical, but there is a marked general similarity.' Finally, blood tests with twelve different sera revealed no difference. There seems to be little doubt, therefore, that the twins were uniovular (Newman, 1940). 
TABLE I

Comparative Measurements of the Two Reported Cases and the Twin Sisters

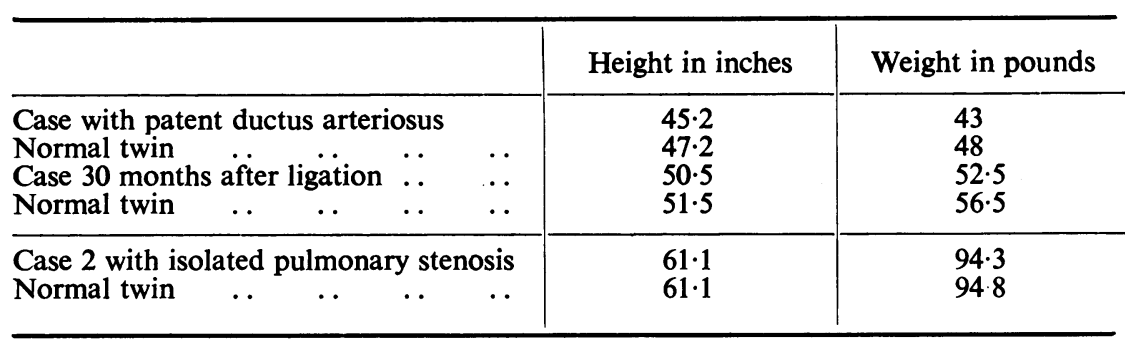

Case 2. The patient, a fourteen-year-old girl, had a twin sister. They were born 6 weeks prematurely but pregnancy and confinement were otherwise uneventful. Both weighed $3 \frac{1}{2} \mathrm{lb}$. at birth. A heart murmur was discovered when she was 18 weeks old but subsequent development was normal and equalled that of her sister. She was able to hold her own with other children and her sister at games and gymnastics.

On examination she was a well developed girl. The cardiac impulse was diffuse and there was a thrill palpable in the second left interspace. There was a loud systolic murmur maximal in the same area and the second sound was poorly heard to the left of the sternum. The blood pressure was 130/70. A teleradiogram (Fig. 2A) showed enlargement of the pulmonary trunk and the right ventricle. An electrocardiogram (Fig. 3) showed changes diagnostic of right ventricular preponderance. The lesion was considered to be isolated pulmonary stenosis.

Comparison of the twin. The twin sister was a normal healthy girl. There was a soft systolic murmur in the pulmonary area, but otherwise the cardiovascular system was normal. The blood pressure was 135/75. A teleradiogram (Fig. 2B) revealed a normal cardiac contour. The electrocardiogram was within normal limits.

It was almost impossible to distinguish the one child from the other, all comparable details being very similar. The finger prints were reported on as follows: "There is a marked similarity in the patterns of comparable fingers, but the prints are not identical." Blood tests showed no serological

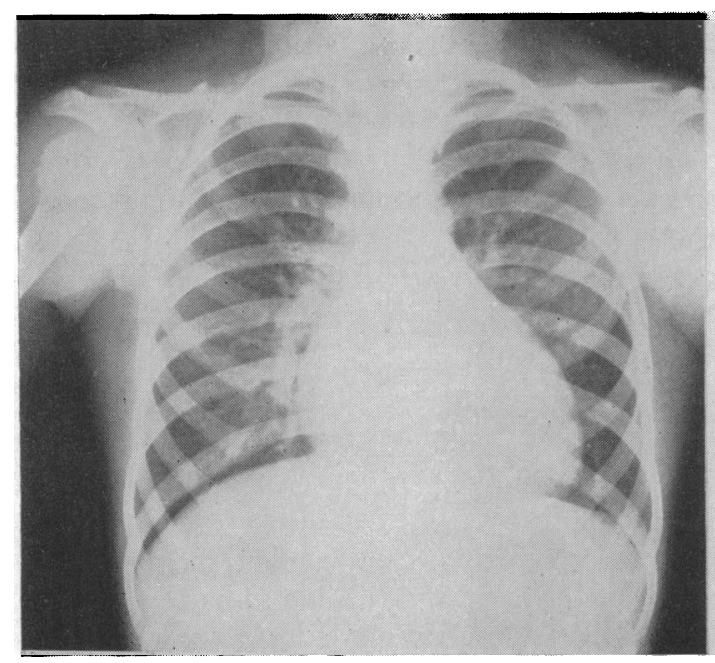

A

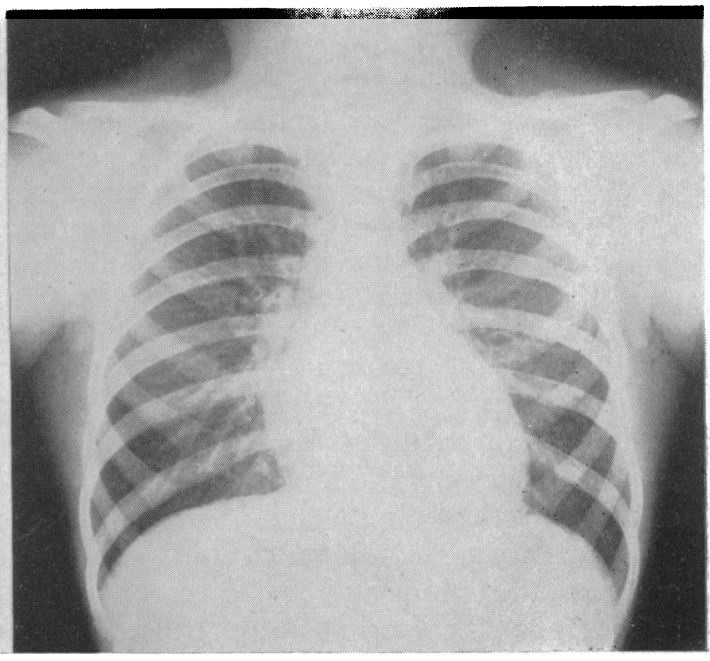

B

FIG. 1.-Comparative teleradiograms of Case 1 (A) and her twin sister (B), fourteen months after closure of the ductus. The heart of the affected child is still larger than her normal twin. 
differences. By the criteria of Newman (1940), therefore, it is highly probable that the twins were uniovular.

The measurements of the two cases and the twin sisters are compared in Table I.

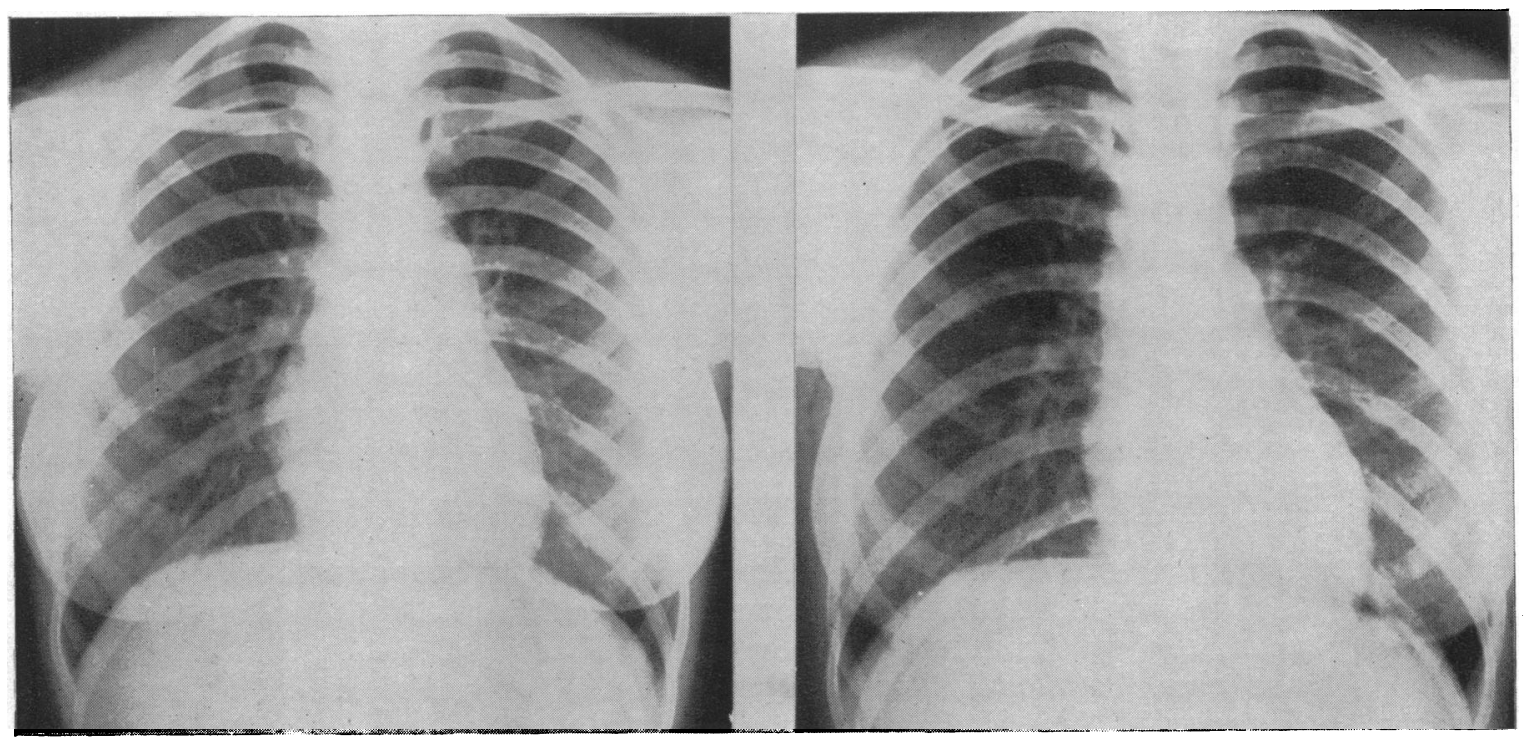

A

\section{B}

FIG. 2.-Comparative teleradiograms of Case 2 (isolated pulmonary stenosis) (A) and her twin sister (B). In the former there is enlargement of the pulmonary artery and the right ventricle.

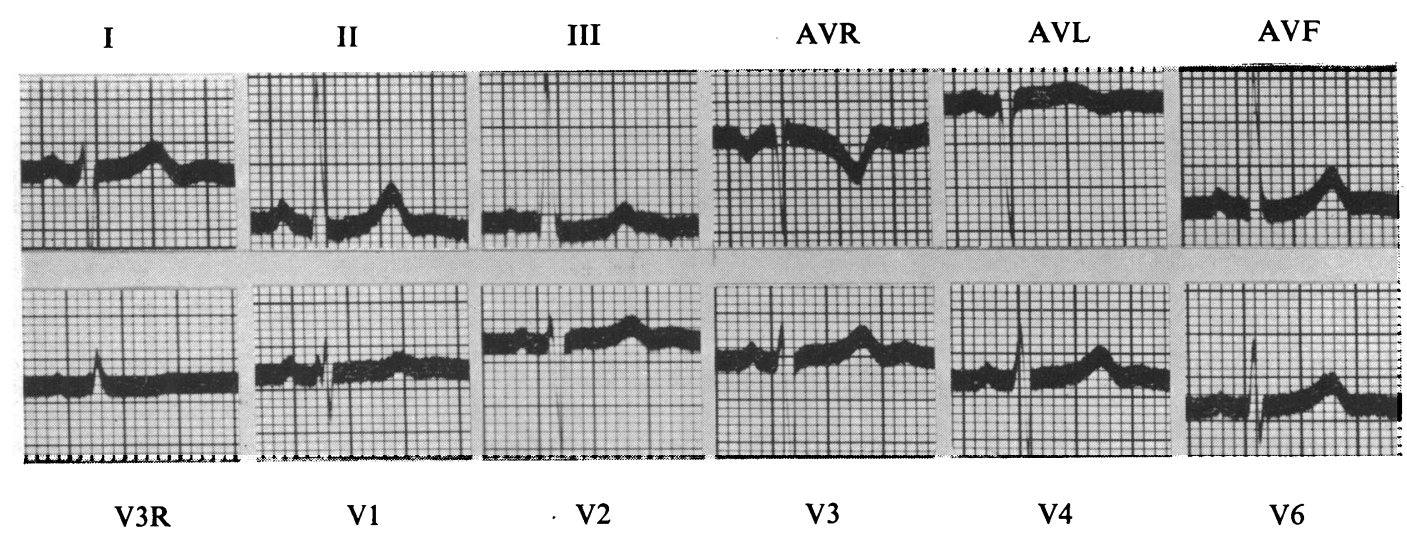

FIG. 3.-The electrocardiogram from Case 2. There is abnormal right axis deviation. The $R$ wave over the right præcordium and the large $\mathrm{S}$ wave over the left præcordium (V2-V4) indicate right ventricular enlargement.

\section{DisCUSSION}

The ætiological factors concerned in congenital heart disease are divided into genetic and environmental. The environmental factors are generally regarded as virus infections, syphilis, avitaminosis, irradiation, or skeletal deformities. Campbell (1949), reporting three hundred cases of congenital heart disease, concluded that the causes were mainly genetic, a conclusion supported by the number of families reported with more than one member exhibiting congenital defects 
(Walker and Ellis, 1940/41; Gilchrist, 1945; Taussig, 1947; Campbell, 1949). Campbell (1949) has stated that some 7 per cent of patients have relatives with congenital defects. Murphy (1940), reviewing the evidence, concluded that malformations, as they occurred in random samples of the population, were due to inherited factors in the germ plasm prior to fertilization.

If these conclusions are correct the same defect must be expected to occur in both of monozygotic twins for they must be genotypically identical. Such cases have been reported many times. An exception to this may be dextrocardia occurring as part of situs inversus, for Newman (1928) has suggested that if twinning occurs at the stage of late gastrulation when differentiation of the right and left sides has already taken place, reversed symmetry may occur. This may account for the case reported by Debreuil-Chambardel (1927).

Other explanations must be sought, therefore, to explain the cases reported in this paper. Firstly, there may be an abnormality of intra-uterine environment which has affected the development of one twin only. Such an explanation cannot account for the undoubted hereditary factor in congenital heart disease and would also seem to be unlikely to influence closure of the ductus, an event that occurs after birth. There was nothing to suggest any of the usual environmental factors in either of the reported cases. Secondly, the gene carrying the defect may be of very low penetration requiring some coincidental environmental change to permit expression. Gates (1946) has pointed out that this may happen, thereby causing differences in monozygotic twins.

This latter theory provides the most acceptable explanation of the known hereditary factors and of these two reported cases. The factors that normally cause closure of the ductus arteriosus are imperfectly known, although Klotz (1907) has stressed the role of pressure changes in the ductus at birth and Kennedy and Clark (1942) have clearly shown the importance of the first inspirations of oxygen: the interplay of these factors must vary considerably from case to case and a certain combination may be necessary to bring about expression of the gene. Pulmonary stenosis differs in that it develops in utero. It is difficult to understand how changes in intra-uterine environment may effect development of only one of two monozygotic embryos, yet the well documented case reported by Penrose (1937) in which congenital syphilitic stigmata were confined to one of such twins, provides good reason for believing that it may do so.

AFFECTED CHILD $\longrightarrow$ NORMAL CHILD $\mathbf{x}-\longrightarrow-\longrightarrow \mathbf{x}$

ARROW INDICATES TIME OF LIGATION OF DUCTUS
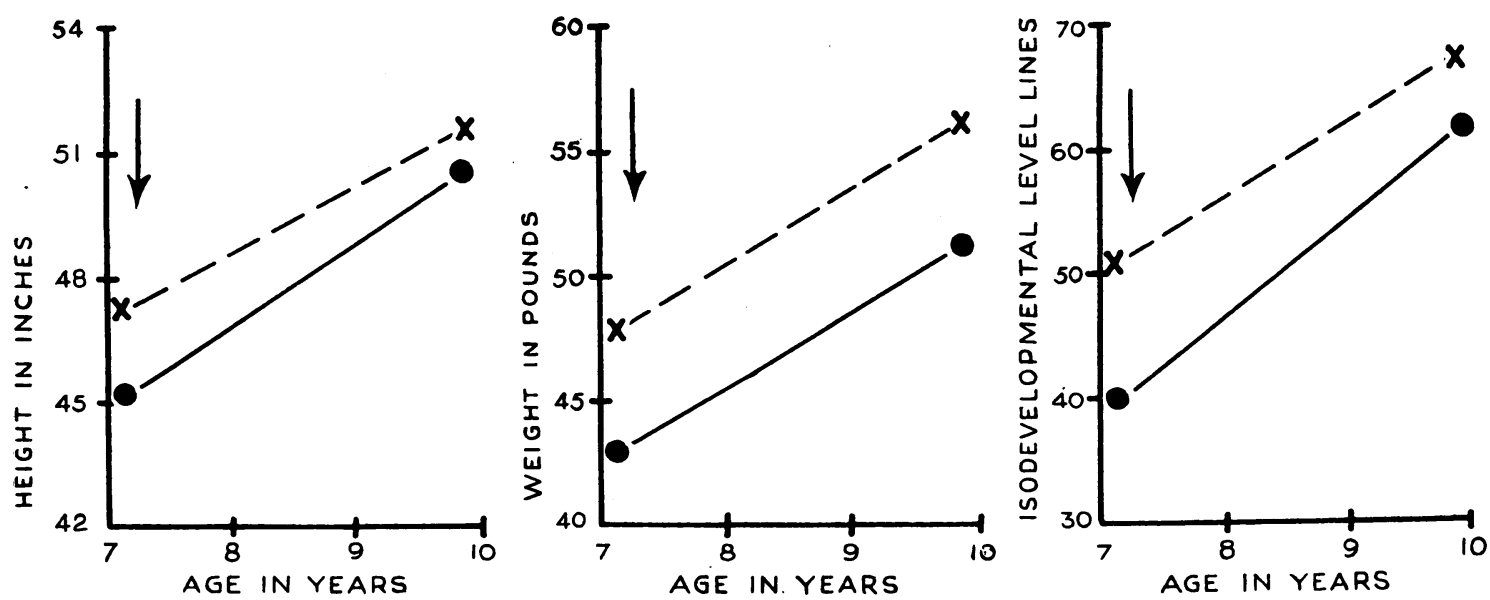

FIG. 4.-Progress of Case 1 and her twin sister during the 30 months after ligation of the ductus. The three graphs show the gains in height, in weight, and in the isodevelopmental level lines of Wetzel. 
A
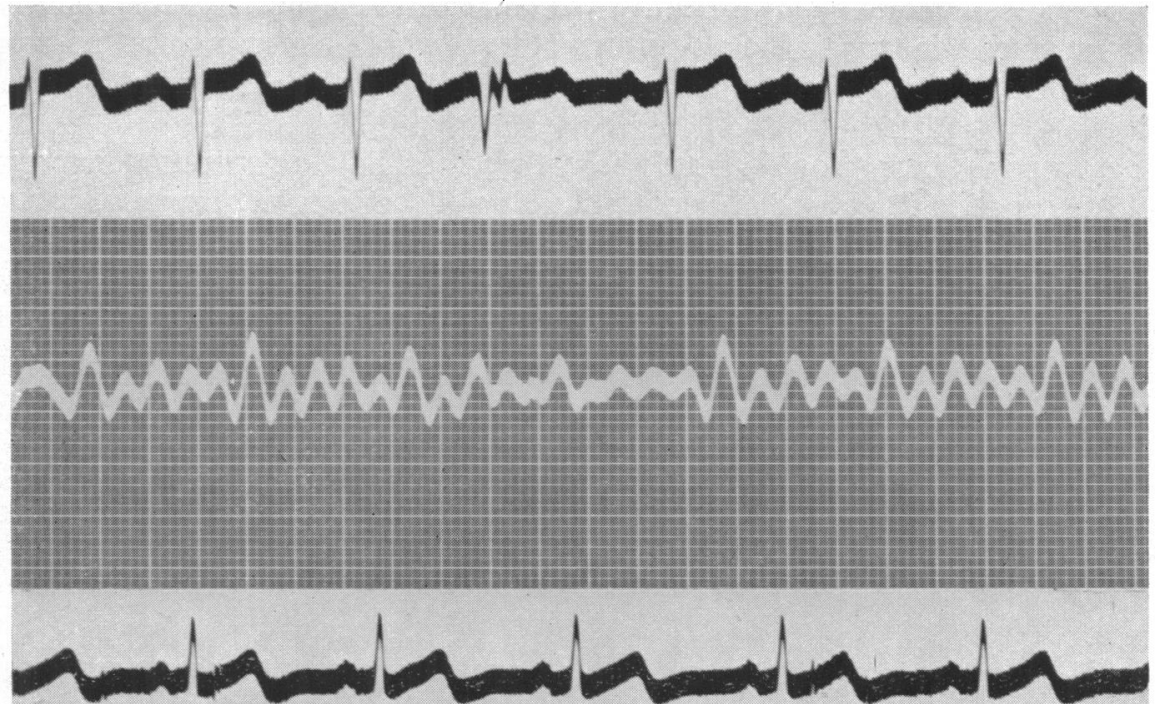

B

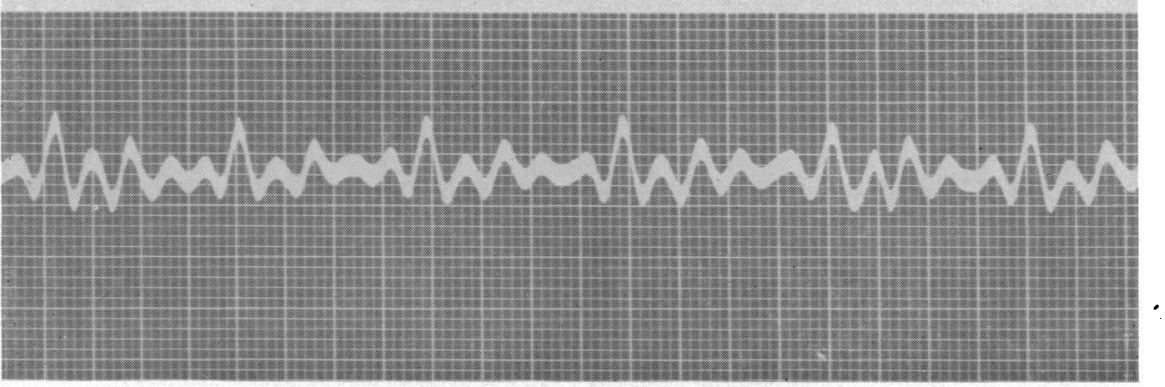

FIG: 5.-Ballistocardiographs from Case 2 with pulmonary stenosis (A) and her twin sister (B). The simultaneous electrocardiograph is lead I in each case.

The biometric studies of Stocks (1930) led him to conclude that a difference in height greater than the appropriate standard deviation was rarely, if ever, found in monozygotic twins. In Case 1, in which the lesion was a patent ductus, the difference in height before operation was 2 inches and the standard deviation 1.6 inches. With the same genetic and, after birth, the same environmental factors in both children, it is reasonable to ascribe the difference in height to the patent ductus. The slender build and underdevelopment of children with this defect has been previously noted by Porter (1947) although not by Benn (1947). Lessening of the systemic flow, due to part being lost into the pulmonary circuit, is generally regarded as being the cause of the impaired development. The volume of the shunt in the reported case was not known, but the heart size suggests that it was of at least moderate dimensions. The pulmonary vasculature, however, was normal.

Following the closure of the ductus the affected child developed more rapidly than the normal child. In Fig. 4 the progress of the children is shown diagrammatically. The three graphs show the gains in height and weight and their progress on the physical fitness grid of Wetzel (1944). In this system, height is plotted against weight and the resultant measured by what are termed " isodevelopmental level lines." These level lines are then plotted against age. The method therefore takes into account both height, weight, and age in assessing development. It will be seen that the affected child advanced 22 level lines, while the normal child advanced only $17 \frac{1}{2}$ during the period of observation. The graphs for height and weight show that this advance was mainly due to a gain in relative 
height without a corresponding gain in relative weight. This is significant, for Verschuer (1928) found that, in monozygotic twins, height was the anthropomorphic measurement least affected by environment. Gilchrist (1945) commented on the increase in growth that may follow successful operation.

Although growth may be improved, or at least rendered normal after operation, our observations suggest that lost ground is made up slowly and possibly not completely. From this point of view, it therefore seems desirable to ligate the ductus as early as possible and especially before the period of rapid growth which is ushered in with the second decade.

In Case 2, in which the lesion was though to be isolated pulmonary stenosis, the physique of both twins was almost identical and normal for their age. Retardation in these cases can only be due to a diminished cardiac output. The good exercise tolerance in this patient must indicate that the output was adequate under almost all conditions. Ballisto-cardiographic studies of both twins suggested that this assumption was correct.* The calculated stroke volume of the affected twin was $41 \mathrm{ml}$. and that of the normal twin $48 \mathrm{ml}$. The cardiac outputs were identical. Apart from the difference in size, the form of the records were very similar (Fig. 5).

\section{SUMMARY}

Two cases of congenital heart disease confined to one of uniovular twins are reported. In one the lesion was a patent ductus arteriosus and in the other isolated pulmonary stenosis:

Development was impaired in the case of patent ductus arteriosus, but not in the case of isolated pulmonary stenosis. Following closure of the ductus, development improved, especially in height, but two and a half years after operation there was still a difference in the physique of the twins.

The genetics of congenital heart disease is briefly reviewed. It is suggested that, in the reported cases, the gene was of low penetration necessitating a coincidental change in environment to permit expression.

I wish to thank Professor Crighton Bramwell for his help and advice; Dr. F. Stratton for his kindness in performing the serological tests; and the Chief Constable of Manchester and the Manchester City Police for taking and reporting upon the finger prints.

Benn, J. (1947). Brit. Heart J., 9, 283.

\section{REFERENCES}

Campbell, M. (1949). Ouart. J. Med., 18, 379.

Debreuil-Chambardel (1927). Presse Med., Paris, 35, 1157.

Gates, R. G. (1946). Human Genetics. New York.

Gilchrist, A. R. (1945). Brit. Heart J., 7, 1.

Kennedy, J. A., and Clark, S. L. (1942). Amer. J. Physiol., 136, 140.

Klotz, O. (1907). Tr. Ass. Amer. Physicians, 22, 213.

Komai, T., and Fukuoka, G. (1934). J. Hered., 25, 423.

Lehmann, W. (1937). Z. Konstlehre, 20, 237.

Lewis, A. (1936). Ann. Eugenics, 7, 58.

Milne, M. D. (1951). Lancet, 1, 204.

Murphy, D. P. (1940). Congenital Malformations. University of Pennsylvania Press.

Newman, H. H. (1928). Biol. Bull., 55, 298.

- (1940). Multiple Human Births. New York.

Penrose, L. S. (1937). Lancet, 1, 322.

Porter, W. B. (1947). Amer. J. med. Sci., 213, 178.

Siemens, H. W. (1927). J. Hered., 18, 201.

Starr, I. (1947). Amer. J. med. Sci., 214, 233.

Rawson, A. J., Schroeder, H. A., and Joseph, N. R. (1939). Amer. J. Physiol., 127, 1.

Stocks, P. (1930). Ann. Eugenics, 4, 49.

Taussig, H. B. (1947). Congenital Malformations of the Heart. New York.

von Verschuer, O. (1928). Zeits. Abst. Vererb. Suppt., 11, 1508.

Walker, G. C., and Eillis, L. B. (1940-41). Proc. New Eng. Heart Ass., pp. 26-27.

Wetzel, N. C. (1944). Growth in Medical Physics. Chicago.

* In these investigations an undamped ballistocardiograph was used of the type described by Starr et al. (1939). The cardiac output was calculated by means of the formula devised by Starr (1947)

$$
\text { Stroke volume }=\sqrt{\mathrm{K} 2 \int I d t+\int J d t \sqrt{ } c}
$$

where $\int I d t$ and $\int J d t$ are the areas in millimetre-seconds of the $\mathrm{I}$ and $\mathrm{J}$ waves respectively, $c=$ the length of the cardiac cycle, and $K$ is a constant. 